\title{
Common changes in autism
}

Our understanding of the genetic contribution to autism spectrum disorders (ASDs) has expanded rapidly, but remains far from complete. Despite good evidence for roles of rare and de novo variants in some cases, the genetic basis of most cases remains unexplained and the involvement of common genetic variants is poorly understood. Two

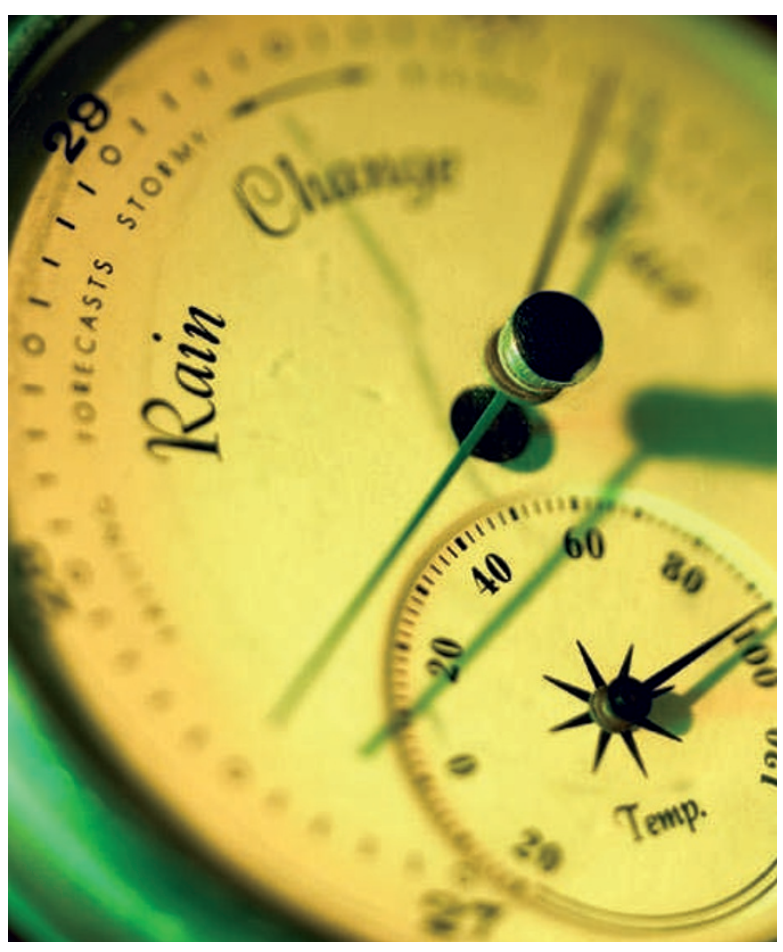

genome-wide studies now alter this picture. One provides the first firm evidence for a role of common singlenucleotide polymorphisms (SNPs) in ASDs, whereas the other expands our knowledge of the involvement of copy number variation.

Wang and colleagues carried out genome-wide studies using two large cohorts, one comprising ASD families and the other population-based. Six SNPs showed association at genome-wide significance across the two cohorts and this was replicated in a third cohort. The SNPs lie between two genes that encode the cell adhesion molecules cadherin 9 and cadherin 10. This is an interesting finding given that altered neuronal cell adhesion has been implicated in ASDs; furthermore, cadherin 10 is expressed in the frontal cortex, an area that is known to be affected in ASD cases.

'Pathway-based' approaches which combine data from SNPs to look for differences in statistical significance between certain groups of genes and the rest of the genome - highlighted a group of 25 cadherin genes and 8 neurexin genes, providing further evidence for a role of altered neuronal cell adhesion in ASDs.

In a second study, Glessner and colleagues looked for copy number variants (CNVs) that are involved in ASD susceptibility. The results provided additional support for the involvement of some CNVs that have already been implicated in ASDs and implicated nine new variants. The genes that are associated with these CNVs again suggest the importance of neuronal cell adhesion in ASD, and also highlight a role for the ubiquitin pathway.

As well as adding to our understanding of the genetic architecture of ASD susceptibility by implicating common variants, these studies provide clues to the biological functions affected in these conditions. Studying the expression patterns and functions of these genes will be a crucial next step.

Louisa Flintoft

Chief Editor, Nature Reviews Genetics

ORIGINAL RESEARCH PAPERS Wang, K. et al.

Common genetic variants on $5 \mathrm{p} 14.1$ associate with autism spectrum disorders. Nature $28 \mathrm{Apr}$ 2009 (doi:10.1038/nature07999) | Glessner, J. T. et al. Autism genome-wide copy number variation reveals ubiquitin and neuronal genes. Nature 28 Apr 2009 (doi: 10.1038/nature07953) FURTHER READING Maestrini, E. et al. High density SNP association study and copy number variation analysis of the AUTS1 and AUTS5 loci implicate the IMMP2L-DOCK 4 gene region in autism susceptibility. Mol. Psychiatry 28 Apr 2009 (doi:10.1038/mp.2009.34) | Ma, D., Salyakina, D. et al. A genome-wide association study of autism reveals a common novel risk locus at $5 \mathrm{p} 14.1$. Ann. Hum. Genet. 28 Apr 2009 (doi:10.1111/j.1469-1809.2009.00523) 